\title{
Molecular Basis of a Dominant SARS-CoV-2 Spike-Derived Epitope Presented by HLA-A*02:01 Recognised by a Public TCR
}

\author{
Christopher Szeto ${ }^{1,2,+}{ }^{1}$, Andrea T. Nguyen ${ }^{1,2,+}$, Christian A. Lobos ${ }^{1,2}$, Demetra S. M. Chatzileontiadou ${ }^{1,2}$, \\ Dhilshan Jayasinghe ${ }^{1,2}$, Emma J. Grant ${ }^{1,2}$, Alan Riboldi-Tunnicliffe ${ }^{3}$, Corey Smith ${ }^{4,5}$ and Stephanie Gras $1,2, *$ (i) \\ 1 Viral and Structural Immunology Laboratory, Department of Biochemistry and Genetics, La Trobe Institute \\ for Molecular Science, School of Molecular Sciences, La Trobe University, Bundoora, VIC 3086, Australia; \\ C.Szeto@latrobe.edu.au (C.S.); A.Nguyen3@latrobe.edu.au (A.T.N.); C.Lobos@latrobe.edu.au (C.A.L.); \\ D.Chatzileontiadou@latrobe.edu.au (D.S.M.C.); D.Jayasinghe@latrobe.edu.au (D.J.); \\ E.Grant@latrobe.edu.au (E.J.G.) \\ 2 Viral and Structural Immunology Laboratory, Department of Biochemistry and Molecular Biology, \\ Biomedicine Discovery Institute, Monash University, Clayton, VIC 3800, Australia \\ 3 Australian Synchrotron, ANSTO, Clayton, VIC 3168, Australia; alanr@ansto.gov.au \\ 4 QIMR Berghofer Centre for Immunotherapy and Vaccine Development and Translational and Human \\ Immunology Laboratory, Department of Immunology, QIMR Berghofer Medical Research Institute, \\ Brisbane, QLD 4006, Australia; corey.smith@qimrberghofer.edu.au \\ 5 Faculty of Medicine, The University of Queensland, Brisbane, QLD 4072, Australia \\ * Correspondence: S.Gras@latrobe.edu.au \\ + The authors contributed equally.
}

\section{check for} updates

Citation: Szeto, C.; Nguyen, A.T.; Lobos, C.A.; Chatzileontiadou, D.S.M.; Jayasinghe, D.; Grant, E.J.; Riboldi-Tunnicliffe, A.; Smith, C.; Gras, S. Molecular Basis of a Dominant SARS-CoV-2 Spike-Derived Epitope Presented by HLA-A*02:01 Recognised by a Public TCR. Cells 2021, 10, 2646. https:/ / doi.org/10.3390/cells10102646

Academic Editor: Mingui Fu

Received: 15 August 2021

Accepted: 28 September 2021

Published: 3 October 2021

Publisher's Note: MDPI stays neutral with regard to jurisdictional claims in published maps and institutional affiliations.

Copyright: (c) 2021 by the authors. Licensee MDPI, Basel, Switzerland. This article is an open access article distributed under the terms and conditions of the Creative Commons Attribution (CC BY) license (https:/ / creativecommons.org/licenses/by/ $4.0 /)$.

\begin{abstract}
The data currently available on how the immune system recognises the SARS-CoV-2 virus is growing rapidly. While there are structures of some SARS-CoV-2 proteins in complex with antibodies, which helps us understand how the immune system is able to recognise this new virus; however, we lack data on how $\mathrm{T}$ cells are able to recognise this virus. T cells, especially the cytotoxic CD8+ T cells, are critical for viral recognition and clearance. Here we report the $\mathrm{X}$-ray crystallography structure of a T cell receptor, shared among unrelated individuals (public TCR) in complex with a dominant spike-derived CD8+ T cell epitope (YLQ peptide). We show that YLQ activates a polyfunctional CD8+ $\mathrm{T}$ cell response in COVID-19 recovered patients. We detail the molecular basis for the shared TCR gene usage observed in HLA-A*02:01+ individuals, providing an understanding of TCR recognition towards a SARS-CoV-2 epitope. Interestingly, the YLQ peptide conformation did not change upon TCR binding, facilitating the high-affinity interaction observed.
\end{abstract}

Keywords: SARS-CoV-2; T cells; epitope presentation; public TCR recognition; YLQ peptide; COVID19 recovered

\section{Introduction}

Severe acute respiratory syndrome coronavirus 2 (SARS-CoV-2) is an emerging virus that has infected over 200 million people worldwide, resulting in coronavirus disease 2019 (COVID-19) and over 4.3 million deaths [1]. Despite the rapid development of effective and safe vaccinations against COVID-19, the global infection rate remains high, likely due to mutations within the SARS-CoV-2 virus, driven by the scale of global infections, and now vaccination, which pressures the virus to select for viral mutations that facilitate immune escape. Cytotoxic T cells are vital in the control and clearance of viral infections [2-5] and have been shown to be an important factor of the immune response to SARS-CoV-2 due to their role in viral clearance and ability to recognise variants of SARS-CoV-2 [6]. CD8+ T cells typically recognise peptides of 8-10 amino acids long presented by human leukocyte antigen (HLA) molecules [7].

To date, over 1,200 distinct CD8+ T cell epitopes have been reported (www.iedb.org (accessed on 6 July 2021) [8]), spanning multiple SARS-CoV-2 proteins. These epitopes 
are restricted by a large range of HLA class I (HLA-I) molecules, including HLA-A*02:01, one of the most prevalent HLAs in the global population [9]. Several studies have shown that HLA-A*02:01+ individuals demonstrate a strong CD8+ T cell response to one such HLA-A*02:01 restricted CD8+ T cell epitope derived from the Spike (S) protein of SARSCoV-2, namely, $\mathrm{S}_{269-277}$ (YLQPRTFLL, hereafter referred to as YLQ) [10-18], which was characterised as an immunodominant epitope [18].

CD8+ T cells recognise the peptide-HLA complex (pHLA) through their T cell receptor (TCR). TCRs comprise an $\alpha$ - and $\beta$-chain, composed of variable $(\mathrm{V})$, joining $(\mathrm{J})$, constant $(\mathrm{C})$ and diversity ( $D ; \beta$-chain only) genes generated by somatic recombination [19]. Additional diversity is introduced by the inclusion of non-template encoded $(\mathrm{N})$ regions at the junction of gene segments by the terminal deoxynucleotidyl transferase (tdt) enzyme, leading to incredible diversity [20]. Indeed, it is estimated that there are $10^{12} \mathrm{TCR}$ combinations, with $2 \times 10^{7}$ TCR present in humans [21]. Within the TCR, three regions of variability, termed complementarity determining regions (CDRs), exist and are responsible for TCR specificity [7]. Of these, the CDR3 region, which spans the V(D)J gene segments, is the most variable [7] and has been shown both functionally and structurally to make the predominant contacts within the pHLA complex [7].

The CDR3 $\alpha \beta$ loops are typically used to define peptide-specific CD8+ T cell clonotypes, and the combination of these clonotypes is referred to as the TCR repertoire. TCR repertoires can exhibit biases, which is a preference for particular TCR $\alpha$-chain Variable (TRAV) or TCR $\beta$-chain Variable (TRBV) usage $[7,22,23]$. Additionally, despite the vast array of potential TCRs in any given individual, identical epitope-specific clonotypes have been described across donors. These "public" TCRs are thought to have a selective advantage or comprise predominately germline-encoded sequences that could be easily generated in different individuals $[7,23-25]$. However, TCR repertoires are more typically private, where each individual displays completely distinct TCR sequences specific for the same epitope [26-28]. Understanding the TCR repertoire, and in the case of public TCRs, how they interact with their pHLA molecule is critical for a thorough understanding of CD8+ T cell response towards specific epitopes.

Here, we wanted to validate and dissect the CD8+ T cell response to the YLQ peptide and determine the structural basis for the presentation of the YLQ peptide by HLA$\mathrm{A}^{*} 02: 01$. Additionally, we aimed to provide the molecular basis of the biased TCR repertoire observed in response to the YLQ epitope in COVID-19 recovered individuals in different studies [16-18]. Therefore, we have selected a representative public TCR, hereafter called YLQ-SG3 TCR. We determined the ternary structure of the HLA-A*02:01-YLQ peptide bound to the public YLQ-SG3 TCR and investigated the binding affinity of the public TCR.

\section{Materials and Methods}

\subsection{Sequence Alignment}

The full spike proteins from the five different coronaviruses were aligned using the online alignment software Rhône-Alpes Bioinformatics Center (PRABI http:/ / www.prabi. $\mathrm{fr} /$ (accessed on 6 August 2021)) and multiple sequence alignment CLUSTALW [29]. The accession number for the sequence used were for SARS-CoV-2: YP_009724390.1, OC43: YP_009555241.1, HKU-1: AZS52618.1, 229E: AAG48592.1, NL63: AAS58177.1. Then the sequence aligned with the SARS-CoV-2 YLQ peptide was selected and reported in Table 1.

Table 1. YLQ homologues peptides from seasonal coronaviruses.

\begin{tabular}{ccc}
\hline Virus & YLQ Homologue & Sequence Identity (\%) \\
\hline SARS-CoV-2 & YLQPRTFLL & - \\
OC43 & PLTSRQYLL & 44 \\
HKU-1 & PLSRRQYLL & 44 \\
229E & ALPKTVREF & 11 \\
NL63 & FGPSSQPYY & 0 \\
\hline
\end{tabular}




\subsection{SARS-CoV-2 YLQ Conservation}

The sequence conservation of the YLQ peptide was obtained using the NCBI website tool "Mutations in SARS-CoV-2 SRA Data" (https:/ / www.ncbi.nlm.nih.gov/labs/virus/ vssi/\#/scov2_snp, which uses the Wuhan-Hu-1 as reference sequence of SARS-CoV-2 with the accession number of NC_045512.2. The website was accessed on the 30 July 2021, with 412,297 full sequences of the spike proteins available, and the identified mutations are reported in Table 2.

\subsection{Generation of Peptide-Specific CD8+ T Cell Lines}

CD8+ T cell lines were generated as previously described [26,30]. In summary, HLA typed HLA-A*02:01+ PBMCs from COVID-19 recovered individuals were incubated with SARS-CoV-2 peptide pools ( $2 \mu \mathrm{M}$ /peptide) and cultured for 10-14 days in RPMI-1640 supplemented with $1 \times$ Non-essential amino acids (NEAA; Thermofisher, Scoresby, Australia), $5 \mathrm{mM}$ HEPES (Thermofisher, Scoresby, Australia), $2 \mathrm{mM}$ L-glutamine (Thermofisher, Scoresby, Australia), $1 \times$ penicillin/streptomycin/glutamine (Thermofisher, Scoresby, Australia), $50 \mu \mathrm{M}$ 2-ME (Sigma-Aldrich, St Louis, MO, USA) and 10\% heat-inactivated FCS (Thermofisher). The cultures were supplemented with 10 IU IL-2 (BD Biosciences, Melbourne, Australia) 2-3 times weekly. CD8+ T cell lines were freshly harvested and used for subsequent assays.

\subsection{Intracellular Cytokine Assay}

The intracellular cytokine assay was performed as previously described [26,30]. Briefly, CD8+ T cell lines were stimulated with cognate peptide pools or $10 \mu \mathrm{M}$ individual peptides (Genscript, Hong Kong, China) and incubated for $5 \mathrm{~h}$ in the presence of GolgiPlug (BD Biosciences), GolgiStop (BD Biosciences) and anti-CD107a-AF488 (BD Biosciences/eBioscience, Melbourne, Australia). Following incubation, the cells were surface stained for $30 \mathrm{~min}$ with anti-CD8-PerCP-Cy5.5 (BD Biosciences/eBioscience), anti-CD4-BUV395 (BD Biosciences), anti-CD14-APCH7, CD19-APCH7 and Live/Dead Fixable Near-IR Dead Cell Stain (Life Technologies, Melbourne, Australia). The cells were then fixed and permeabilised for 20 min using BD Cytofix/Cytoperm solution (BD Biosciences) and intra-cellularly stained with anti-IFN- $\gamma$-BV421 and anti-TNF-PE-Cy7 (all BD Biosciences) for a further $30 \mathrm{~min}$. The cells were acquired on a BD LSRFortessa with FACSDiva software (version 6.1.3, BD Biosciences). The analysis was performed using FlowJo software (version 10.7.1, BD Biosciences), where cytokine levels identified in the R0 control condition were subtracted from corresponding test conditions.

\subsection{Protein Refold, Purification, Crystallisation}

The HLA-A*02:01 heavy chain and $\beta 2$-microglobulin, as well as both chains of the YLQ-SG3 TCR, were produced using bacterial expression of inclusion bodies and refolded into a soluble protein (for detailed protocol see [31]). In brief, DNA plasmids encoding each recombinant protein subunit (HLA-A*02:01 $\alpha$-chain, $\beta 2$-microglobulin, TCR $\alpha$-chain and TCR $\beta$-chain) were individually transformed into competent BL21 E. coli cells. All cells were grown separately, and their inclusion bodies were extracted. Soluble HLA-A*02:01YLQ complex was produced by refolding inclusion bodies in the following amounts: $30 \mathrm{mg}$ of $\alpha$-chain, $10 \mathrm{mg}$ of $\beta 2$-microglobulin and $4 \mathrm{mg}$ of YLQ peptide (Genscript, Hong Kong, China). Soluble YLQ-SG3 TCR was produced by refolding $50 \mathrm{mg}$ of TCR $\alpha$ chain with 50 $\mathrm{mg}$ of TCR $\beta$ chain. The refold buffer used was $3 \mathrm{M}$ Urea, $0.5 \mathrm{M}$ L-Arginine, $0.1 \mathrm{M}$ Tris- $\mathrm{HCl}$ $\mathrm{pH}$ 8.0, $2.5 \mathrm{mM}$ EDTA pH 8.0, $5 \mathrm{mM}$ glutathione (reduced) and $1.25 \mathrm{mM}$ glutathione (oxidised). The refold mixtures were separately dialysed into $10 \mathrm{mM}$ Tris- $\mathrm{HCl} \mathrm{pH}$ 8.0. HLA-A*02:01-YLQ was purified using anion exchange chromatography (HiTrap Q, Cytiva, Marlborough, MA, USA), whilst the YLQ-SG3 TCR was purified using anion exchange followed by size exclusion chromatography (Superdex 200 16/60, Cytiva, Marlborough, MA, USA). 
Crystals of HLA-A*02:01-YLQ complex were obtained using the sitting-drop, vapourdiffusion method at $20{ }^{\circ} \mathrm{C}$ with a protein/mother liquor drop ratio of $1: 1$ at $6 \mathrm{mg} / \mathrm{mL}$ in $10 \mathrm{mM}$ Tris- $\mathrm{HCl} \mathrm{pH} 8.0,150 \mathrm{mM} \mathrm{NaCl}$ using 20\% PEG3350 and $0.2 \mathrm{M} \mathrm{NaF}$. YLQ-SG3 TCR was co-complexed with HLA-A*02:01-YLQ by combining both proteins at a 1:1 molar ratio before purification using size exclusion chromatography (Superdex 200 10/30, GE). Crystals of YLQ-SG3 TCR-HLA-A*02:01-YLQ complex were obtained using the sittingdrop, vapour-diffusion method at $20^{\circ} \mathrm{C}$ with a protein/mother liquor drop ratio of 1:1 at $3 \mathrm{mg} / \mathrm{mL}$ in $10 \mathrm{mM}$ Tris- $\mathrm{HCl} \mathrm{pH}$ 8.0, $150 \mathrm{mM} \mathrm{NaCl}$ using 20\% PEG3350 and $0.05 \mathrm{M}$ Zn-Acetate. The crystals were soaked in a cryosolution of 30\% $(w / v)$ PEG3350 diluted using mother liquor and then flash-frozen in liquid nitrogen. The data were collected on the MX2 beamline at the Australian Synchrotron, part of ANSTO, Australia [32].

\subsection{Structure Determination}

The data were processed using XDS [33], and the structures were determined by molecular replacement using the PHASER program [34] from the CCP4 suite [35] using a model of HLA-A*02:01 without peptide (derived from PDB ID: 3GSO [36]). Manual model building was conducted using COOT [37], followed by refinement with BUSTER [38]. The final models have been validated and deposited using the wwPDB OneDep System, and the final refinement statistics, PDB codes are summarised in Table 3. All molecular graphics representations were created using PyMOL (Schrodinger, LLC, v1.7.6.3, New York, NY, USA).

\subsection{Stability Assay}

Thermal stability was measured using differential scanning fluorimetry, performed in a Qiagen RG6 rtPCR. HLA-A*02:01-YLQ was heated from 30 to $95^{\circ} \mathrm{C}$ at a rate of $0.5^{\circ} \mathrm{C} / \mathrm{min}$ with excitation and emission channels set to yellow (excitation of $\sim 530 \mathrm{~nm}$ and detection at $\sim 557 \mathrm{~nm}$ ). The experiment was performed at two concentrations $(5$ and $10 \mu \mathrm{M})$ in duplicate. Each sample was dialysed in $10 \mathrm{mM}$ Tris- $\mathrm{HCl} \mathrm{pH} \mathrm{8.0,150} \mathrm{mM} \mathrm{NaCl}$ and contained a final concentration of 10X SYPRO Orange Dye. Fluorescence intensity data were normalised and plotted using GraphPad Prism 9 (version 9.1.1, GraphPad Software, San Diego, CA, USA).

\subsection{Surface Plasmon Resonance (SPR)}

SPR was performed using a Biacore T200 biosensor at $25^{\circ} \mathrm{C}$. YLQ-SG3 TCR was immobilised onto a CM5 chip using amine coupling, with the reference flow cell containing a negative control (M158-66 TCR [23]). The immobilisation steps were carried out at a flow rate of $5 \mu \mathrm{L} / \mathrm{min}$ in immobilisation buffer $10 \mathrm{mM}$ HEPES (pH 7.0), $150 \mathrm{mM} \mathrm{NaCl}$, and finally blocked with Ethanolamine at $5 \mu \mathrm{L} / \mathrm{min}$ for $7 \mathrm{~min}$. HLA-A*02:01-YLQ was injected over the chip at a range of concentrations from 0.2 to $50 \mu \mathrm{M}$ using a 1 in 2 dilution at a flow rate of $30 \mu \mathrm{L} / \mathrm{min}$ and in a running buffer of $10 \mathrm{mM}$ Tris- $\mathrm{HCl} \mathrm{pH}$ 8.0, $150 \mathrm{mM} \mathrm{NaCl}$, $1 \mathrm{mg} / \mathrm{mL}$ bovine serum albumin and $0.005 \%$ P20. All injections were run in duplicate, and SPR was performed twice to determine the dissociation constant between YLQ-SG3 TCR and HLA-A*02:01-YLQ $(n=2)$ using both steady-state affinity measurements and kinetics data. Kinetics data were analysed using the T200 BiaEvaluation software (version 3.0, Cytiva, Marlborough, MA, USA), whilst steady-state values were extracted using T200 BiaEvaluation software (version 3.0, Cytiva, Marlborough, MA, USA), plotted and fitted into a one-site specific binding non-linear regression using Graphpad Prism (version 9.1.1.).

\section{Results}

\subsection{The YLQ Epitope Induced a Polyfunctional CD8+ T Cell Response in COVID-19 Recovered Donors}

The CD8+ T cell response towards the HLA-A*02:01 restricted YLQ peptide has previously been reported $[10,11,16-18]$; however, data regarding the level of polyfunctionality associated with the CD8+ T cell response has been limited in COVID-19 recovered donors. Therefore, we first tested the immunogenicity of the YLQ peptide in three COVID-19 
recovered individuals by expanding $\mathrm{CD} 8+\mathrm{T}$ cells against peptide pools, including the YLQ peptide and performed an intracellular cytokine staining assay to determine the immunogenicity. The CD8+ T cell response and cytokine production towards the YLQ peptide was variable between the COVID-19 recovered donors. CD8+ T cells from two out of three donors, namely Q036 and Q042, were able to produce all four cytokines, while only double cytokine-producing CD8+ T cells were observed in the Q062 donor (Figure 1 and Figure S1). Even though the level of polyfunctionality was different between the three donors, they were all able to generate a polyfunctional CD8+ T cell response specific to the YLQ peptide after recovery from COVID-19.
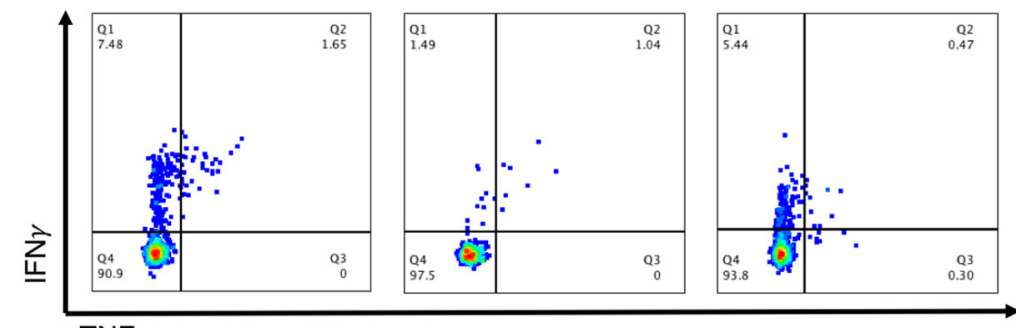

TNF
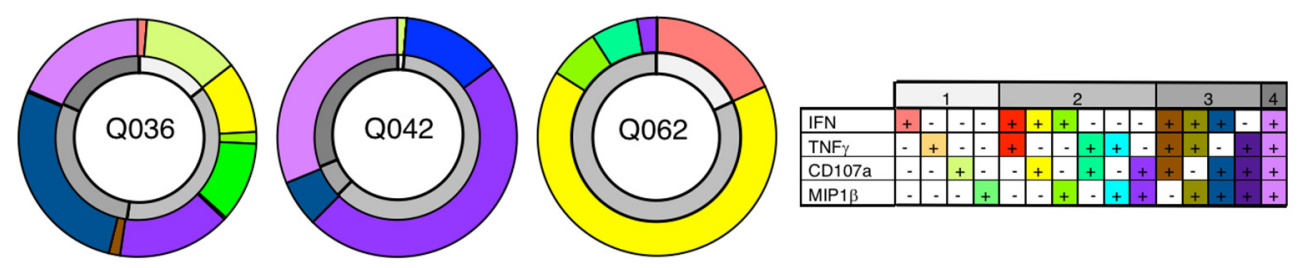

Figure 1. Polyfunctional response from YLQ-specific CD8+ T cells. The top panels are representative FACs plots for each donor (Q036, Q042 and Q062) showing IFN $\gamma$ and TNF production from CD8+ T cells against the YLQ peptide. The bottom panels represent the polyfunctionality level of CD8+ T cells for the same COVID-19 recovered donors as the top panel. The outside ring, in colour, shows the $\%$ of cytokine combinations produced by CD8+ T cells, while the inner ring (in grey) represents the number of functions produced by CD8+ T cells. The keys for each colour are in the bottom-right table.

\subsection{The Conserved YLQ Peptide Is Stably Presented by the HLA-A*02:01 Molecule}

We previously determined that a high level of CD8+ T cell activation towards a SARS$\mathrm{CoV}-2$ epitope derived from the nucleocapsid ( $\mathrm{N}_{105-113}$ or SPR peptide) was underpinned by a pre-existing and cross-reactive response [26]. This pre-existing immunity was due to a high level of sequence identity (55-89\%) between the SPR peptide from SARS-CoV-2 and its homologues from seasonal coronaviruses. Therefore, we questioned if the YLQ peptide was also conserved in seasonal coronaviruses by aligning the spike protein sequences of SARS-CoV-2 and seasonal coronaviruses (Table 1).

While the SPR peptide had up to $89 \%$ sequence identity with its seasonal coronaviruses derived homologues, the level of conservation of the YLQ peptide was lower. The YLQ peptide shared only four residues with its homologues from OC43 and HKU-1 $\beta$-coronaviruses, with two of those residues being primary anchor residues that will be buried in the HLA cleft. The low sequence identity is in line with the lack or weak T cell activation observed in healthy individuals [18].

As the YLQ peptide is derived from spike protein, which is relatively less conserved and more prone to mutation than other SARS-CoV-2 viral proteins, we also wanted to assess the level of mutations found in the different SARS-CoV-2 isolates (Table 2). Interestingly, this dominant $\mathrm{T}$ cell epitope was conserved with less than $0.5 \%$ of mutations for any of its residues. 
Table 2. YLQ conservation in SARS-CoV-2 isolates (non-synonymous mutation).

\begin{tabular}{|c|c|c|c|c|c|c|c|c|c|}
\hline Residue & $Y$ & L & $\mathbf{Q}$ & $\mathbf{P}$ & $\mathbf{R}$ & $T$ & F & L & L \\
\hline mutation & $\begin{array}{c}\mathrm{H} \\
(0.006 \%) \\
\mathrm{D} \\
(0.005 \%) \\
\mathrm{C} \\
(0.005 \%)\end{array}$ & $\begin{array}{c}\mathrm{V} \\
(0.005 \%)\end{array}$ & $\begin{array}{c}\mathrm{K} \\
(0.005 \%) \\
\mathrm{E} \\
(0.003 \%) \\
\mathrm{R} \\
(0.009 \%) \\
\mathrm{L} \\
(0.002 \%)\end{array}$ & $\begin{array}{c}S \\
(0.012 \%) \\
L \\
(0.431 \%) \\
H \\
(0.012 \%)\end{array}$ & $\begin{array}{c}\mathrm{K} \\
(0.014 \%) \\
\mathrm{M} \\
(0.009 \%) \\
\mathrm{S} \\
(0.021 \%)\end{array}$ & $\begin{array}{c}\mathrm{S} \\
(0.004 \%) \\
\mathrm{I} \\
(0.014 \%)\end{array}$ & $\begin{array}{c}\mathrm{L} \\
(0.002 \%)\end{array}$ & & \\
\hline$\%$ variant & 0.016 & 0.005 & 0.021 & 0.456 & 0.045 & 0.018 & 0.002 & 0 & 0 \\
\hline
\end{tabular}

In order to gain a deeper understanding of the YLQ peptide recognition by CD8+ $T$ cells, we first refolded and crystallised the HLA-A*02:01-YLQ complex and solved its structure at a high resolution (Table 3 ). The electron density map was clear for the peptide, indicating a stable and rigid conformation of the YLQ peptide in the HLA-A*02:01 cleft (Figure 2A,B).
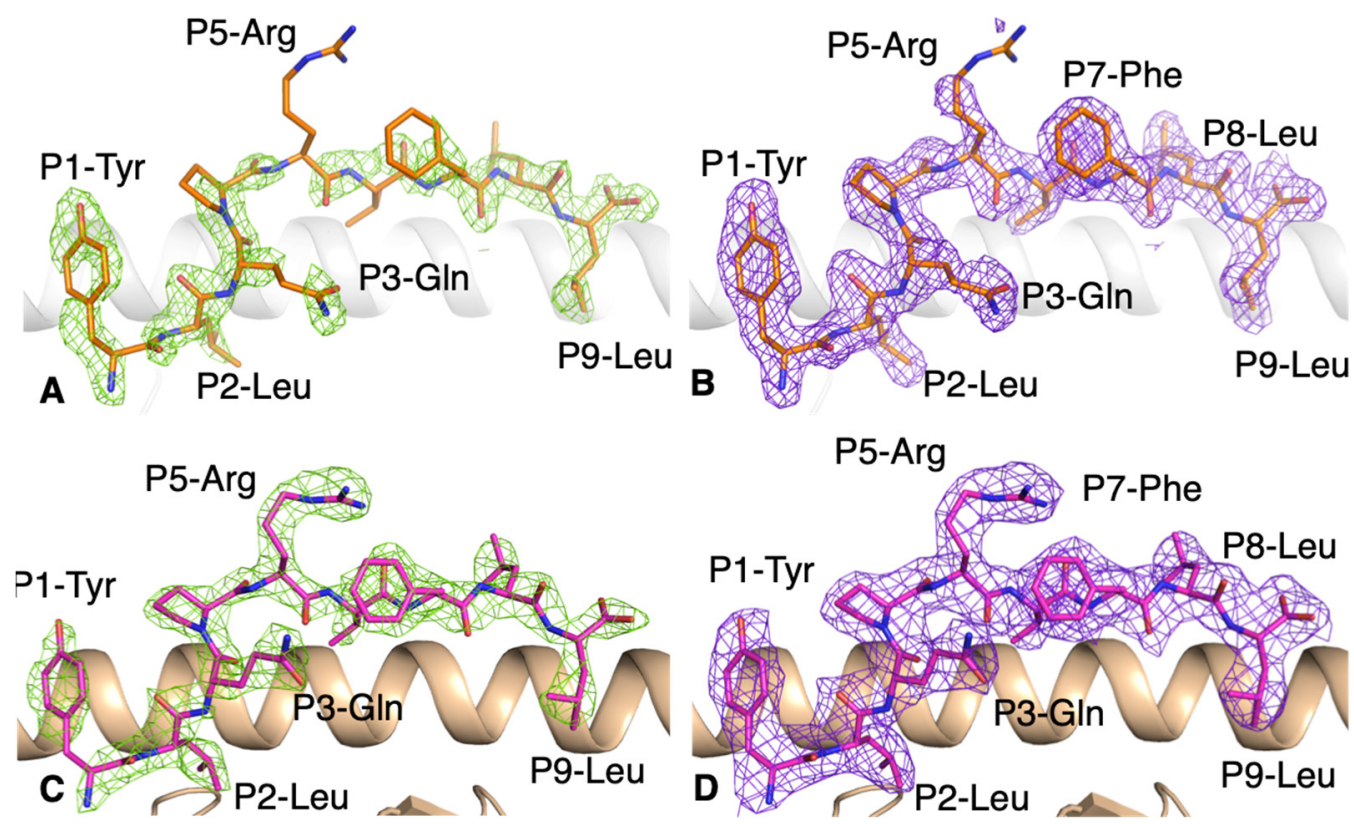

Figure 2. Electron density map for the YLQ peptide bound to HLA-A*02:01 without and with the YLQ-SG3 TCR. (A,B) Electron density map of (A) Fo-FC map at $3 \sigma$ (green) and (B) 2Fo-FC at $1 \sigma$ (purple) around the YLQ peptide (orange stick) in complex with HLA-A*02:01 (white cartoon). (C,D) Electron density maps of (C) Fo-Fc map at $3 \sigma$ (green) and (D) 2Fo-Fc at $1 \sigma$ (purple) around the YLQ peptide (pink stick) presented by the HLA-A*02:01 (beige cartoon) bound to the YLQ-SG3 TCR.

The YLQ peptide bound to the HLA-A*02:01 cleft via canonical primary anchors of small hydrophobic residues, P2-Leu and P9-Leu, characteristic of HLA-A*02:01, and an additional secondary anchor with P3-Gln (Figure 2A,B). The YLQ peptide has a series of residues with long, solvent-exposed side-chains, P1-Tyr, P5-Arg, P7-Phe and P8-Leu, that could potentially interact with TCRs. The side-chains were well defined in the electron density map; this is possibly due to the numerous intra-peptide contacts. The only exception was the P5-Arg for which the density was partly missing for the side-chain, showing high mobility (Figure 2B). This rigidity of the pHLA was apparent when we undertook a thermal stability assay to determine the stability of the overall peptide-HLA (pHLA) complex, as this is important for immunogenicity (30). Indeed, the thermal stability of 
the HLA-A*02:01-YLQ complex was about $60{ }^{\circ} \mathrm{C}$, which is similar to that observed for the dominant influenza-derived $\mathrm{M}_{58-66}$ peptide bound to HLA-A*02:01 [23,30].

Table 3. Data collection and refinement statistics.

\begin{tabular}{|c|c|c|}
\hline Data Collection Statistics & HLA-A*02:01-YLQ & YLQ-SG3 TCR HLA-A*02:01-YLQ \\
\hline Space group & $\mathrm{P} 22_{1}$ & $\mathrm{C} 2$ \\
\hline Cell Dimensions $(\mathrm{a}, \mathrm{b}, \mathrm{c})(\AA)$ & $54.09,80.12,58.50$ & $225.36,49.62,91.72, \beta=91.83^{\circ}$ \\
\hline Resolution $(\AA)$ & $47.43-2.05(2.11-2.05)$ & $48.68-2.60(2.72-2.60)$ \\
\hline Total number of observations & $92,231(7410)$ & $140,103(16,773)$ \\
\hline $\mathrm{Nb}$ of unique observation & $27,671(2172)$ & $31,710(3800)$ \\
\hline Multiplicity & $3.3(3.4)$ & $4.4(4.4)$ \\
\hline Data completeness (\%) & $97.5(97.8)$ & $100(99.9)$ \\
\hline $\mathrm{I} / \sigma_{\mathrm{I}}$ & $8.6(2.1)$ & $7.0(2.2)$ \\
\hline $\mathrm{R}_{\text {pim }}{ }^{\mathrm{a}}(\%)$ & $6.7(43.8)$ & $7.5(49.3)$ \\
\hline $\mathrm{CC}_{1 / 2}$ & $0.993(0.593)$ & $0.992(0.823)$ \\
\hline \multicolumn{3}{|l|}{ Refinement Statistics } \\
\hline $\mathrm{R}_{\text {factor }} \mathrm{b}(\%)$ & 19.6 & 19.1 \\
\hline $\mathrm{R}_{\text {free }} \mathrm{b}(\%)$ & 23.4 & 23.5 \\
\hline \multicolumn{3}{|l|}{ rmsd from ideality } \\
\hline Bond lengths $(\AA)$ & 0.01 & 0.01 \\
\hline Bond angles $\left({ }^{\circ}\right)$ & 1.07 & 1.18 \\
\hline \multicolumn{3}{|l|}{ Ramachandran plot (\%) } \\
\hline Favoured & 99.0 & 95.1 \\
\hline Allowed & 0.01 & 4.7 \\
\hline Disallowed & 0 & 0.2 \\
\hline PBD code & 7RDT & 7RTR \\
\hline
\end{tabular}

\subsection{The Dominant YLQ Peptide Is Recognised by Public TCRs}

The YLQ peptide was reported to be immunogenic in $\sim 90 \%$ of COVID-19 recovered individuals, while only $5 \%$ of healthy donors exhibited T cells specific for the peptide [18]. This shows that in the absence of an antibody response, this epitope can be used as a marker of infection in HLA-A*02:01+ patients, and also that a T cell-driven immune response would be activated. Interestingly, three studies have reported the TCR sequences of YLQ-specific clonotypes from COVID-19 recovered individuals and show a highly biased repertoire among unrelated donors (Table 4).

Table 4. YLQ-specific biased TCR repertoire.

\begin{tabular}{|c|c|c|c|c|}
\hline Study & TRAV & $\operatorname{CDR} 3 \alpha$ & TRBV & CDR3 $\beta$ \\
\hline [18] & $\begin{array}{l}12-1(74.7 \%) \\
12-2(10.1 \%)\end{array}$ & $\begin{array}{l}\text { CAVNDDKIIF, CAVNxDDKIIF, } \\
\text { CAVNxxDDKIIF }(23 \%) \\
\text { CAVNxDDKIIF }(48.4 \%)\end{array}$ & $\begin{array}{c}7-9(21.3 \%) \\
20-1(13.6 \%) \\
2(12.2 \%)\end{array}$ & $\begin{array}{c}\text { CASSPDIxxxF } \\
(32 \%)\end{array}$ \\
\hline [17] & $\begin{array}{c}12-1(23.9 \%) \\
12-2(3.5 \%)\end{array}$ & $\begin{array}{c}\text { CVVNxD, CVVNxxD/N } \\
(65.8 \%) \\
\text { CAVNxDDKIIF }(100 \%)\end{array}$ & $\begin{array}{c}7-9(12.6 \%) \\
20-1(20.1 \%) \\
2(12.1 \%)\end{array}$ & $\begin{array}{c}\text { CASSPDIEAFF } \\
(33 \%)\end{array}$ \\
\hline [16] & $\begin{array}{l}12-1(58.3 \%) \\
12-2(33.3 \%)\end{array}$ & $\begin{array}{l}\text { CVVNDx, CVVNxDN, } \\
\text { CVVNxxN }(37.5 \%) \\
\text { CAVNxDDKIIF }(50 \%)\end{array}$ & $\begin{array}{c}7-9(17.6 \%) \\
20-1(5.8 \%) \\
2(23.5 \%)\end{array}$ & $\begin{array}{c}\text { CASSPDIEAFF } \\
(100 \%)\end{array}$ \\
\hline $\begin{array}{c}\text { YLQ-SG3 } \\
{[16,18]}\end{array}$ & $12-2$ & CAVNRDDKIIF & $7-9$ & CASSPDIEQYF \\
\hline
\end{tabular}

x: Represents any residue at that position. The \% for each TRAV, TRBV or CDR motif represent the frequency of those from the overall repertoire in each of the three studies. 
We analysed the TCR sequences from those studies and observed the same TCR gene usage bias, especially for the TCR $\alpha$-chain. The HLA-A*02:01-YLQ-specific T cells were mostly expressing a TRAV12-1 or TRAV12-2 allele for their $\alpha$-chain, both sharing $50 \%$ sequence identity for their CDR $1 \alpha$ and CDR2 $\alpha$ loops. The most frequent TRBV gene expressed by YLQ-specific CD8+ T cells were 2, 7-9 and 20-1, with different frequencies depending on the study (Table 4). Interestingly, there were conserved motifs present in both $\alpha$ and $\beta$ CDR3 loops, with a public TCR observed among donors and across studies, here called the YLQ-SG3 TCR (Table 4). The YLQ-SG3 TCR was composed of the TRAV12-2 and TRBV7-9 bias chain and contained the conserved motif within both its CDR3 loops. We, therefore, chose the public YLQ-SG3 TCR to understand how T cells can engage with YLQ epitope, a SARS-CoV-2 spike-derived peptide presented by the HLA-A*02:01 molecule.

\subsection{Structure of the Public YLQ-SG3 TCR Recognising the Dominant YLQ Epitope Presented by} HLA- $A^{*} 02: 01$

We refolded and purified the YLQ-SG3 TCR and undertook affinity measurements by surface plasmon resonance (SPR), as well as solved the structure of the YLQ-SG3 TCR in complex with the HLA-A*02:01-YLQ.

The SPR data shows that the YLQ-SG3 TCR binds with the HLA-A*02:01-YLQ complex with high affinity and a Kd of $2.09 \pm 0.16 \mu \mathrm{M}$ (Figure 3A,B), at the high end of the affinity range observed for $\mathrm{CD} 8+\mathrm{TCR}$ [7]. In addition, the kinetics of the interaction show a fast association $\left(\mathrm{k}_{\mathrm{on}}=386,800 \pm 25,000 \mathrm{M}^{-1} \mathrm{~s}^{-1}\right)$ and a fast dissociation $\left(\mathrm{koff}=0.679 \pm 0.001 \mathrm{~s}^{-1}\right)$ compared to other TCRs [27] (Figure 3A).

We solved the structure of the YLQ-SG3 TCR in complex with the HLA-A*02:01YLQ to better understand how TCRs recognise the SARS-CoV-2 epitope. We solved the structure at a resolution of $2.6 \AA$ (Table 3) with an unambiguous density for the peptide (Figure 2C,D).

The YLQ-SG3 TCR docks diagonally above the centre of the YLQ peptide with a docking angle of $73^{\circ}$ (Figure 3C), within the range of other TCR-pHLA complexes [7]. The buried surface area at the interface of the TCR and HLA-A*02:01-YLQ was $1809 \AA$, also within the range (average of $1885 \AA$ ) [7]. Interestingly, and consistent with the strong TCR bias observed for the YLQ-specific T cells, the TCR $\alpha$-chain is contributing to $67 \%$ of the interaction (Figure 3B), with the CDR $1 / 2 \alpha$ loops contributing to $40 \%$ of the total interactions and giving the molecular basis for the TRAV12 bias observed (Table 4). All $\mathrm{CDR} \alpha$ loops contacted the HLA-A*02:01 molecule; however, from these, only CDR $1 \alpha$ and CDR3 $\alpha$ contacted the YLQ peptide (Table 5).

The CDR $1 \alpha$ loop stretched itself above the N-terminal region of the $\alpha 2$-helix and forms a salt bridge with Glu166 via Arg28 $\alpha$, as well as hydrogen bonds with the Gln155 via the Gln $37 \alpha$ and Ser $38 \alpha$. In addition, the side-chain of the Gln $37 \alpha$ dips in between the HLA $\alpha 2$-helix and the peptide backbone to form an extensive hydrogen bond network (Figure $4 \mathrm{~A}$ ). The CDR2 $\alpha$ sits above the $\alpha 2$-helix of the HLA just before the hinge region of the $\alpha 2$-helix, with the Ser58 $\alpha$ forming H-bond with Arg157 outside the cleft, and the Tyr57 forming Van der Waals bonds with the Gln155 inside the cleft (Figure 4B). The CDR3 $\alpha$ makes limited contributions to forming contacts with the HLA molecule, with the conserved Asp109 $\alpha$ (Table 5) forming a salt bridge with the Arg65 (Figure 4C). 

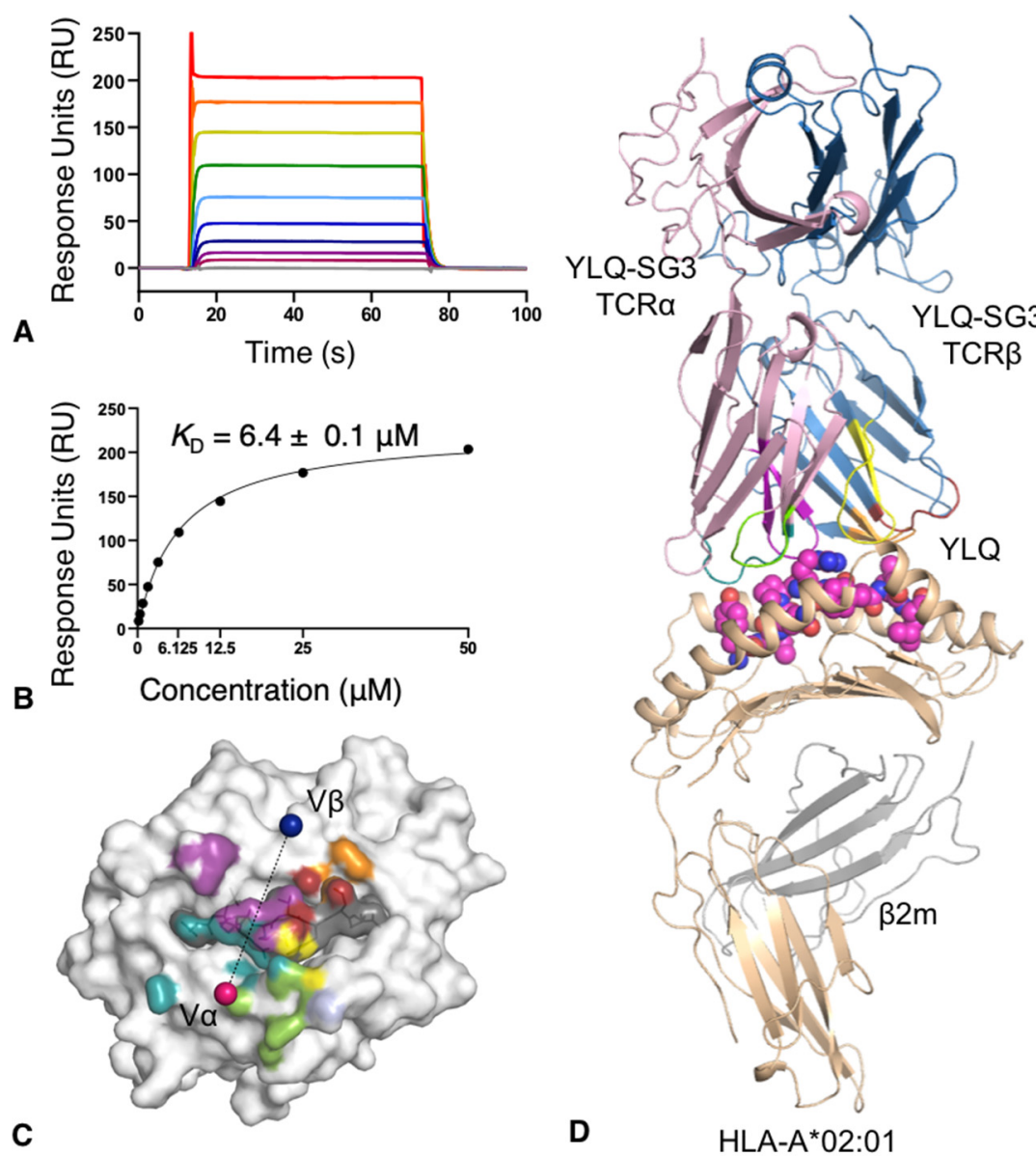

C

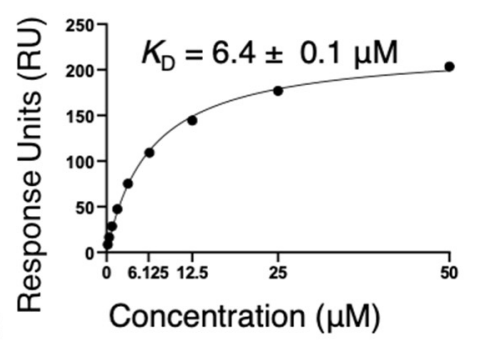

HLA-A*02:01

Figure 3. YLQ-SG3 TCR affinity and structure with HLA-A*02:01-YLQ. (A) SPR sensorgram and (B) steady-state binding curve for YLQ-SG3 TCR towards HLA-A*02:01-YLQ. Analyte HLA-A*02:01YLQ flowed over immobilised YLQ-SG3 TCR with a concentration range of 0.19 to $50 \mu \mathrm{M}$. (C) The footprint of the YLQ-SG3 TCR shows atomic contact with the HLA-A*02:01-YLQ complex. The surface of HLA-A*02:01 is white, the surface of the YLQ peptide is grey. Each atom is coloured by the TCR segment they are contacted by, which for the CDR1/2/3 $\alpha$ is deep teal, chartreuse and purple, for the CDR $1 / 2 / 3 \beta$ is red, orange and yellow and the $\beta$-chain framework is light blue. The pink and blue spheres represent the mass centre of the $\alpha$ - and $\beta$-chain, respectively. (D) The overview of the YLQ-SG3 TCR ( $\alpha$-chain in pink, $\beta$-chain in blue) is represented as cartoon on the top of the YLQ peptide (pink spheres) presented by the HLA-A*02:01 (beige cartoon, with the $\beta 2 \mathrm{~m}$ in grey cartoon). The TCR CDR loops are coloured as per panel C.

Table 5. Contacts between the YLQ-SG3 TCR and HLA-A*02:01-YLQ complex.

\begin{tabular}{|c|c|c|c|}
\hline TCR Segment & TCR Residues & HLA-A*02:01 Residues & Type Bond \\
\hline $\mathrm{CDR} 1 \alpha$ & $\operatorname{Arg} 28^{\mathrm{N} \eta 1-\mathrm{N} \varepsilon}$ & Glu166 ${ }^{\mathrm{O} \varepsilon 2-\mathrm{O} \varepsilon 1}$ & VDW, SB \\
\hline $\operatorname{CDR} 1 \alpha$ & $\mathrm{G} \ln 37^{\mathrm{N} \varepsilon 2}$ & $\mathrm{Gln} 155^{\mathrm{O}}$, Tyr159 & VDW, HB \\
\hline $\mathrm{CDR} 1 \alpha$ & $\mathrm{Ser} 38^{\mathrm{O} \gamma}$ & $\mathrm{G} \ln 155^{\mathrm{O} \varepsilon 1}$ & VDW, HB \\
\hline $\mathrm{FW} \alpha$ & Phe55 & His151 & VDW \\
\hline $\mathrm{CDR} 2 \alpha$ & Tyr57 & Glu154, Gln155, Ala158 & VDW \\
\hline $\mathrm{CDR} 2 \alpha$ & Ser58 $\mathrm{O} \gamma$ & Glu154 ${ }^{\mathrm{O} \varepsilon 2}, \operatorname{Arg} 157^{\mathrm{N \eta} 2}$ & VDW, HB \\
\hline $\mathrm{CDR} 3 \alpha$ & Asp109 ${ }^{\mathrm{O} \delta 1-\mathrm{O} \delta 2}$ & $\operatorname{Arg} 65^{\mathrm{N} \varepsilon-\mathrm{N} \eta 2}$, Lys66 & VDW, SB \\
\hline CDR1 $\beta$ & Arg38 & Thr73 & VDW, HB \\
\hline CDR2 $\beta$ & $\mathrm{G} \ln 57^{\mathrm{N} \varepsilon 2}$ & Thr73 ${ }^{\mathrm{O} \gamma 1}$, Val76 & VDW \\
\hline
\end{tabular}


Table 5. Cont.

\begin{tabular}{|c|c|c|c|}
\hline TCR Segment & TCR Residues & HLA-A*02:01 Residues & Type Bond \\
\hline CDR2 $\beta$ & Asn58 & Val76 & VDW \\
\hline CDR3 $\beta$ & Asp109O82 & Ala150, Gln155 & VDW, HB \\
\hline $\mathrm{CDR} 3 \beta$ & Ile110 & Gln115 & VDW \\
\hline TCR Segment & TCR Residues & YLQ Peptide Residues & Type Bond \\
\hline $\mathrm{CDR} 1 \alpha$ & Asp27 $\mathrm{O} \delta 1$ & $\mathrm{Tyr} 1 \mathrm{OH}$ & $\mathrm{HB}$ \\
\hline $\mathrm{CDR} 1 \alpha$ & Gly29 & Tyr1, Pro4 & VDW \\
\hline CDR1 $\alpha$ & $\mathrm{G} \ln 37^{\mathrm{O} 81}$ & $\mathrm{Gln} 3^{\mathrm{N} \varepsilon 2}, \operatorname{Pro} 4, \operatorname{Arg} 5$ & VDW, HB \\
\hline $\operatorname{CDR} 1 \alpha$ & Ser38 & Arg5 & VDW \\
\hline $\mathrm{CDR} 3 \alpha$ & Asn107 & Arg5 & VDW \\
\hline $\mathrm{CDR} 3 \alpha$ & Asp109O-O 10 & Pro4, $\operatorname{Arg} 5^{\mathrm{N} \varepsilon-\mathrm{N} \eta 1}$ & VDW, HB, SB \\
\hline $\mathrm{CDR} 3 \alpha$ & Asp $110^{\mathrm{O} \delta 1-\mathrm{O} \delta 2}$ & Arg5, Thr6 $6^{\mathrm{O}-\mathrm{N}-\mathrm{O} \gamma}$ & VDW, HB \\
\hline CDR1 $\beta$ & Asn37 & Leu8 & VDW \\
\hline CDR1 $\beta$ & $\operatorname{Arg} 38^{\mathrm{N} \eta 2}$ & Arg5, Thr6 $^{\mathrm{O}}$, Leu8 & VDW, HB \\
\hline $\mathrm{CDR} 2 \beta$ & Gln57 & Leu8 & VDW \\
\hline CDR3 $\beta$ & Asp $109^{\mathrm{O}-\mathrm{O} \delta 2-\mathrm{O} \delta 1}$ & $\mathrm{Arg} 5^{\mathrm{N} \eta 1-\mathrm{N} \eta 2}$, Leu8 & VDW, HB, SB \\
\hline CDR3 $\beta$ & Ile110 & Arg5 & VDW \\
\hline
\end{tabular}

Abbreviations are as follows: FW, framework residue; HB, hydrogen bond (cut-off distance $3.5 \AA$ ); $\mathrm{SB}$, salt bridge (cut-off distance $5 \AA$ )); VDW, van der Waals (cut-off distance $4 \AA$ ).

The YLQ-SG3 TCR $\beta$-chain has limited contact with the HLA. Both CDR1 $\beta$ and CDR2 $\beta$ loops made contacts with two residues of the $\alpha 1$-helix and the CDR3 $\beta$ loop with two residues of the $\alpha$-helix (Table 5).

The YLQ peptide made a significant contribution to the pHLA buried surface area at $38 \%$ and is contacted by five of the CDR loops (Figure 3C and Table 5), whilst the average buried surface area is only $29 \%$ for other solved TCRpMHC complexes [7]. The CDR1 $\alpha$ loop runs over half of the peptide, making contacts from P1-Tyr to P5-Arg, with the side-chain of the Gln37 $\alpha$ inserting itself between the peptide and $\alpha 2$-helix and interacting with P3-Gln, P4-Pro and P5-Arg (Figure 4D). In the same fashion, the CDR3 $\alpha$ loop contacts a large stretch of the YLQ peptide, including P4-Pro, P5-Arg and P6-Thr, and inserts a conserved CDR3 $\alpha{ }^{109} \mathrm{DD}^{110}$ motif in between the peptide and the $\alpha 1$-helix of the HLA$\mathrm{A}^{*} 02: 01$ (Figure $4 \mathrm{E}$ ). The $\mathrm{CDR} 1 \beta$ and CDR2 $\beta$ loops each projected long side-chains towards the C-terminal parts of the peptide surface. As a result, the exposed P8-Leu is surrounded by $A s n 37 \beta / \operatorname{Arg} 38 \beta$ on one side and by $\operatorname{Gln} 57 \beta / A s n 58 \beta$ on the other side. The CDR3 $\beta$ pushes the P5-Arg down with the Ile110 $\beta$ and forms a salt bridge with the Asp109 $\beta$. This conformation is helped by the short length of the CDR3 $\beta$ loop that only forms a short rigid loop due to the Pro108 $\beta$. The P5-Arg is surrounded by the CDR $1 / 3 \alpha$ and CDR1/3 $\beta$ loops (Figure 4F), and instead of wrapping the side-chain of the P5-Arg with CDR loops that have been previously observed [39], the YLQ-SG3 TCR pushes down on the P5-Arg and P6-Phe side-chains. This increased contact surface between the peptide and these loops stabilise the P5-Arg side-chain, yet, do not disturb the HLA-A ${ }^{*} 02: 01$ cleft structure (root mean square deviation of $0.22 \AA$ ). Overall, the YLQ-SG3 TCR docks onto HLA-A*02:01-YLQ with minimal structural rearrangements, with the exception of a few residue side-chains. As the kinetics data from SPR shows a fast association rate (Figure 3A), high binding affinity and moderate dissociation rate. This is consistent with the larger binding interface but minimal structural rearrangements during binding. 


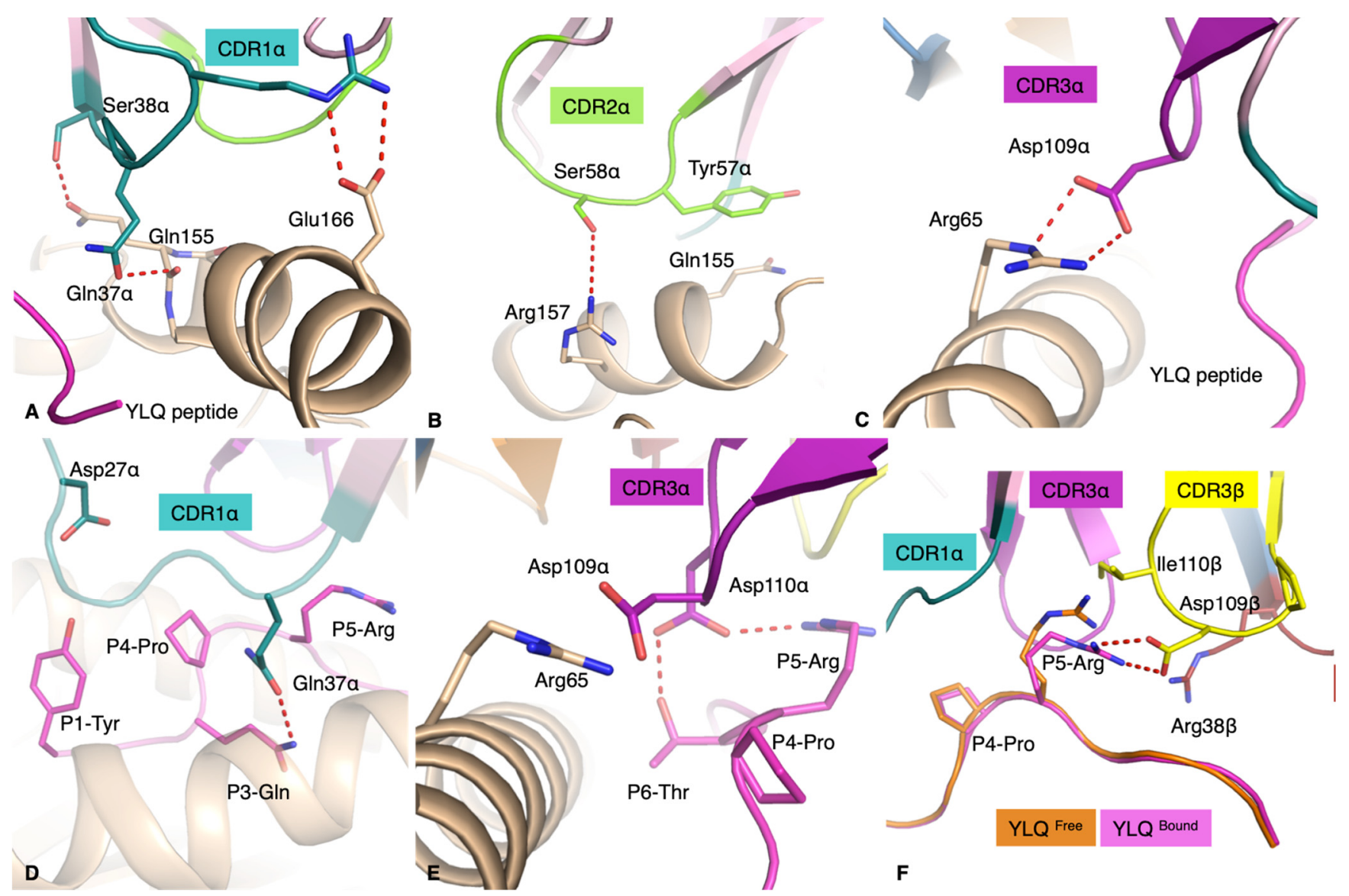

Figure 4. YLQ-SG3 TCR interaction with the HLA-A*02:01 molecule and the YLQ peptide. All the panels show the interaction between the YLQ-SG3 TCR with the $\alpha$-chain in pale pink; the $\beta$-chain in pale blue; the CDR1/2/3 $\alpha$ loops in deep teal, chartreuse and purple, respectively; and the CDR1/2/3 $\beta$ coloured in red, orange and yellow, respectively. The HLA-A*02:01 is coloured in beige, and the YLQ peptide is either in pink when bound to the YLQ-SG3 TCR or orange if free. The red dashed lines represent hydrogen bonds. (A) CDR1 $\alpha$ (deep teal) interacting with the $\alpha 2$-helix of the HLA-A*002:01, with the YLQ peptide in pink cartoon. (B) CDR2 $\alpha$ (chartreuse) interacting with the $\alpha 2$-helix of the HLA before the hinge region of the molecule. (C) CDR3 $\alpha$ loop forming a salt bridge with the HLA Arg65 residue, the YLQ peptide is in pink cartoon. (D) CDR $1 \alpha$ Gln37 $\alpha$ inserting its side-chain in between the HLA (beige cartoon) and the peptide backbone (pink) maximising the surface interaction with the peptide. (E) CDR3 $\alpha$ forming a network of hydrogen bonds with the YLQ peptide. (F) Superposition of the YLQ peptide structures with (pink) and without (orange) the YLQ-SG3 TCR, also showing the interaction of the CDR3 $\beta$ (yellow) with the peptide (pink).

\section{Discussion}

We have described here the molecular basis of a public TCR recognising a dominant spike-derived SARS-CoV-2 epitope. The structure of the YLQ peptide in the cleft of the HLA-A*02:01 molecule is a constrained and rigid peptide that forms numerous intrapeptide interactions favoured by large side-chain residues. This rigidity was consistent with the high thermal stability observed for the HLA-A*02:01-YLQ complex. This rigid conformation of the YLQ peptide did not undergo large structural changes, besides the stabilisation of the P5-Arg, upon the YLQ-SG3 TCR docking. Despite a solvent-exposed P5-Arg, the side-chain of this residue was pushed down by the CDR3 $\beta$ loop to maximise the contact between the TCR and the YLQ peptide. This resulted in a large contribution of the peptide to the pHLA surface buried area of $38 \%$, well above the average of $29 \%$ [7], highlighting the importance of the peptide in driving the interaction with the YLQ-SG3 TCR. 
The YLQ-specific T cells exhibited a bias in their TCR repertoire with frequent usage of the TRAV12 gene for the $\alpha$-chain. Here, we show the molecular basis behind this bias, as the TCRpHLA complex structure shows that the $\alpha$-chain dominates this interaction, contributing to $67 \%$ of the TCR contact surface. This was mainly due to a large footprint of the CDR $1 \alpha(26 \%)$ on the peptide, CDR2 $\alpha(14 \%)$ on the HLA and CDR3 $\alpha(19 \%)$ that binds both the peptide and the HLA.

Interestingly, TRAV12 usage in TCRs that recognise HLA-A*02:01 has been observed in $45 \%$ of the TCRpHLA-A*02:01 structures solved $(17 / 38)$, with $18 \%(7 / 38)$ using the TRAV12-2*01 gene [7]. While the TRAV12+ TCRs all used their $\alpha$-chains to contact the N-terminal parts of the peptide and the HLA-A*02:01 cleft, their CDR1 $\alpha$ loops do not necessarily share the same interactions. For example, although the CDR $1 \alpha$ loop of the CD8 [40] and 868 TCRs [41] interact similarly to the CDR1 $\alpha$ of YLQ-SG3 TCR, the DMF5 TCR uses its CDR1 $\alpha$ loop mainly to contact the peptide N-terminal part [42] and not the HLA. Another example is the NYE_S1 TCR, which docks with a tilt that pushes the CDR1 $\alpha$ loop away from the pHLA and does not make contact [43]. This shows that while some common interactions between the TRAV12+ TCRs and the HLA-A*02:01 are consistent between some TCRs, there is also a large variability of docking modes for the same $\alpha$ TCR segment.

The malleability of docking while using the same or similar sequence between different TCR chains show that the conserved motif observed in the YLQ-specific TCRs, while not identical, could lead to the same mode of recognition of the YLQ epitope. The sequence differences between these TCRs could be important to give the TCR repertoire enough breadth to recognise variants of the YLQ peptide, which could be critical in recognising emerging mutations located in this region of the spike.

The YLQ epitope has been identified as one of the dominant CD8+ T cell epitopes in individuals expressing the HLA-A*02:01 allele. Information about the immune response to the YLQ epitope will be critical in understanding the potential of the YLQ peptide as a targetable epitope for $T$ cell-based therapeutics, biomarkers or vaccines against COVID19. Firstly, the YLQ peptide is highly immunogenic in most COVID-19 recovered HLA$\mathrm{A}^{*} 02: 01+$ individuals and weakly or not recognised in healthy individuals [18], so in the absence of antibodies, this could be used as a marker of infection. Secondly, none of the current mutations reported for that region of the spike are within the Variant of Concern (VOC) or of Interest (VOI). The YLQ epitope selects for biased and public TCRs [22] that could give a selective advantage to HLA-A*02:01+ individuals. The public TCR exhibits a high affinity within the range of other potent anti-viral CD8+ T cells [7], and finally, we report here that in COVID-19 recovered individuals, there is a polyfunctional response from CD8+ T cell stimulated with the YLQ peptide. The ability of the YLQ epitope to strongly stimulate CD8+ T cells has also been observed in vaccinated individuals [44]. Altogether this makes the YLQ peptide a promising target to prime and boost CD8+ T cells against SARS-CoV-2 infection.

Supplementary Materials: The following are available online at https: / www.mdpi.com/article/ 10.3390/cells10102646/s1. Figure S1. Gating strategy used in this study. (A) Gating strategy used to assess the functional responses of CD8+ T cell lines. Cells were gated on lymphocytes, singlets, CD3+Live cells, CD8+CD4- T cells to observe IFN $\gamma$ and TNF production. (B) Gating strategy used to assess the polyfunctional responses of CD8+ T cell lines. Cells were gated on lymphocytes, singlets, CD3+Live cells, CD8+CD4- T cells and each of CD8+IFN $\gamma+, \mathrm{CD} 8+\mathrm{TNF}+, \mathrm{CD} 8+\mathrm{MIP} 1 \beta$ and CD8+CD107a.

Author Contributions: Conceptualisation, S.G.; methodology, C.S. (Corey Smith), A.T.N., D.J. and S.G.; software, A.R.-T. and C.S. (Christopher Szeto); validation, C.S. (Christopher Szeto), A.T.N. and S.G.; formal analysis, C.S. (Corey Smith), A.T.N. and S.G.; investigation, C.S. (Corey Smith), A.T.N. and S.G.; resources, C.S. (Christopher Szeto), C.S. (Corey Smith) and S.G.; data curation, C.A.L. and D.S.M.C.; writing - original draft preparation, S.G.; writing-review and editing, C.S. (Christopher Szeto), A.T.N., E.J.G. and S.G.; visualisation, C.S. (Christopher Szeto), A.T.N. and S.G.; supervision, 
S.G.; project administration, S.G.; funding acquisition, C.S. (Christopher Szeto), C.S. (Corey Smith) and S.G. All authors have read and agreed to the published version of the manuscript.

Funding: This work was supported by generous donations from the QIMR Berghofer COVID-19 appeal, and financial contributions from Monash and La Trobe Universities, Australian Nuclear Science and Technology Organisation (ANSTO, AINSE ECR grants, AINSE PGRA), Australian Research Council (ARC), National Health and Medical Research Council (NHMRC) and the Medical Research Future Fund (MRFF). A.T.N. is supported by a Monash Biomedicine Institute PhD scholarship and an AINSE Ltd. Postgraduate Research Award (PGRA). E.J.G was supported by an NHMRC CJ Martin Fellowship (\#1110429) and is supported by an Australian Research Council DECRA (DE210101479). S.G. is supported by and NHMRC SRF (\#1159272).

Institutional Review Board Statement: This study was performed according to the principles of the Declaration of Helsinki. Ethics approval to undertake the research was obtained from the QIMR Berghofer Medical Research Institute Human Research Ethics Committee HEC21097 (approved 6 July 2021) and Monash University Human Research Ethics Committee 19079 (approved 3 November 2019). COVID-19-recovered donors were over the age of 18 , had been clinically diagnosed by PCR with SARS-CoV-2 infection, and had subsequently been released from isolation following resolution of symptomatic infection, and recruited in May and June 2020 from the south-east region of Queensland, Australia. The majority of participants were returned overseas travellers. Blood samples were collected from all participants to isolate peripheral blood mononuclear cells (PBMCs).

Informed Consent Statement: Informed consent was obtained from all subjects involved in the study.

Data Availability Statement: The final crystal structure models for the YLQ-HLA-A*02:01 and YLQSG3 TCR-HLA-A*02:01-YLQ complexes have been deposited to the Protein Data Bank (PDB) under the following accession codes: 7RDT and 7RTR, respectively.

Acknowledgments: The authors would like to thank Queensland Health Forensic \& Scientific Services, Queensland Department of Health who provided the SARS-CoV-2 isolate QLD02; Monash Macromolecular Crystallisation Facility; MX team for assistance at the Australian Synchrotron and the Australian Cancer Research Foundation (ACRF) Eiger detector. The authors would also like to thank all the participants who took part in the study.

Conflicts of Interest: The authors declare no conflict of interest.

\section{References}

1. Dong, E.; Du, H.; Gardner, L. An interactive web-based dashboard to track COVID-19 in real time. Lancet Infect. Dis. 2020, 20, 533-534. [CrossRef]

2. McMichael, A.J.; Gotch, F.M.; Noble, G.R.; Beare, P.A.S. Cytotoxic T-Cell Immunity to Influenza. N. Engl. J. Med. 1983, 309, 13-17. [CrossRef] [PubMed]

3. Wang, Z.; Wan, Y.; Qiu, C.; Quiñones-Parra, S.; Zhu, Z.; Loh, L.; Tian, D.; Ren, Y.; Hu, Y.; Zhang, X.; et al. Recovery from severe H7N9 disease is associated with diverse response mechanisms dominated by CD8+ T cells. Nat. Commun. 2015, 6, 6833. [CrossRef] [PubMed]

4. Grant, E.; Quiñones-Parra, S.M.; Clemens, E.B.; Kedzierska, K. Human influenza viruses and CD8+ T cell responses. Curr. Opin. Virol. 2016, 16, 132-142. [CrossRef] [PubMed]

5. Sridhar, S.; Begom, S.; Bermingham, A.; Hoschler, K.; Adamson, W.; Carman, W.; Bean, T.; Barclay, W.; Deeks, J.; Lalvani, A. Cellular immune correlates of protection against symptomatic pandemic influenza. Nat. Med. 2013, 19, 1305-1312. [CrossRef]

6. Geers, D.; Shamier, M.C.; Bogers, S.; den Hartog, G.; Gommers, L.; Nieuwkoop, N.N.; Schmitz, K.S.; Rijsbergen, L.C.; van Osch, J.A.; Dijkhuizen, E.; et al. SARS-CoV-2 variants of concern partially escape humoral but not T-cell responses in COVID-19 convalescent donors and vaccinees. Sci. Immunol. 2021, 6, eabj1750. [CrossRef]

7. Szeto, C.; Lobos, C.A.; Nguyen, A.T.; Gras, S. TCR Recognition of Peptide-MHC-I: Rule Makers and Breakers. Int. J. Mol. Sci. 2020, 22, 68. [CrossRef]

8. Vita, R.; Mahajan, S.; Overton, J.A.; Dhanda, S.K.; Martini, S.; Cantrell, J.R.; Wheeler, D.K.; Sette, A.; Peters, B. The Immune Epitope Database (IEDB): 2018 update. Nucleic Acids Res. 2019, 47, D339-D343. [CrossRef]

9. Ellis, J.M.; Henson, V.; Slack, R.; Ng, J.; Hartzman, R.J.; Hurley, C.K. Frequencies of HLA-A2 alleles in five U.S. population groups: Predominance of $A * 02011$ and identification of HLA-A $* 0231$. Hum. Immunol. 2000, 61, 334-340. [CrossRef]

10. Agerer, B.; Koblischke, M.; Gudipati, V.; Montano-Gutierrez, L.F.; Smyth, M.; Popa, A.; Genger, J.W.; Endler, L.; Florian, D.M.; Mühlgrabner, V.; et al. SARS-CoV-2 mutations in MHC-I-restricted epitopes evade CD8(+) T cell responses. Sci. Immunol. 2021, 6, eabg6461. [CrossRef] 
11. Gallerani, E.; Proietto, D.; Dallan, B.; Campagnaro, M.; Pacifico, S.; Albanese, V.; Marzola, E.; Marconi, P.; Caputo, A.; Appay, V.; et al. Impaired Priming of SARS-CoV-2-Specific Naive CD8(+) T Cells in Older Subjects. Front. Immunol. 2021, 12, 693054. [CrossRef]

12. Gangaev, A.; Ketelaars, S.L.C.; Isaeva, O.I.; Patiwael, S.; Dopler, A.; Hoefakker, K.; De Biasi, S.; Gibellini, L.; Mussini, C.; Guaraldi, G.; et al. Identification and characterization of a SARS-CoV-2 specific CD8(+) T cell response with immunodominant features. Nat. Commun. 2021, 12, 2593. [CrossRef]

13. Kared, H.; Redd, A.D.; Bloch, E.M.; Bonny, T.S.; Sumatoh, H.; Kairi, F.; Carbajo, D.; Abel, B.; Newell, E.W.; Bettinotti, M.P.; et al. SARS-CoV-2-specific CD8+ T cell responses in convalescent COVID-19 individuals. J. Clin. Investig. 2021, 131, e145476. [CrossRef]

14. Saini, S.K.; Hersby, D.S.; Tamhane, T.; Povlsen, H.R.; Amaya Hernandez, S.P.; Nielsen, M.; Gang, A.O.; Hadrup, S.R. SARS-CoV-2 genome-wide $\mathrm{T}$ cell epitope mapping reveals immunodominance and substantial CD8(+) T cell activation in COVID-19 patients. Sci. Immunol. 2021, 6, eabf7550. [CrossRef] [PubMed]

15. Tarke, A.; Sidney, J.; Kidd, C.K.; Dan, J.M.; Ramirez, S.I.; Yu, E.D.; Mateus, J.; da Silva Antunes, R.; Moore, E.; Rubiro, P.; et al. Comprehensive analysis of $\mathrm{T}$ cell immunodominance and immunoprevalence of SARS-CoV-2 epitopes in COVID-19 cases. Cell Rep. Med. 2021, 2, 100204. [CrossRef]

16. Minervina, A.A.; Komech, E.A.; Titov, A.; Koraichi, M.B.; Rosati, E.; Mamedov, I.Z.; Franke, A.; Efimov, G.A.; Chudakov, D.M.; Mora, T.; et al. Longitudinal high-throughput TCR repertoire profiling reveals the dynamics of T-cell memory formation after mild COVID-19 infection. eLife 2021, 10, e63502. [CrossRef] [PubMed]

17. Nguyen, T.H.O.; Rowntree, L.C.; Petersen, J.; Chua, B.Y.; Hensen, L.; Kedzierski, L.; van de Sandt, C.E.; Chaurasia, P.; Tan, H.X.; Habel, J.R.; et al. CD8 ${ }^{+} \mathrm{T}$ cells specific for an immunodominant SARS-CoV-2 nucleocapsid epitope display high naive precursor frequency and TCR promiscuity. Immunity 2021, 54, 1066-1082. [CrossRef] [PubMed]

18. Shomuradova, A.S.; Vagida, M.S.; Sheetikov, S.A.; Zornikova, K.V.; Kiryukhin, D.; Titov, A.; Peshkova, I.O.; Khmelevskaya, A.; Dianov, D.V.; Malasheva, M.; et al. SARS-CoV-2 Epitopes Are Recognized by a Public and Diverse Repertoire of Human T Cell Receptors. Immunity 2020, 53, 1245-1257. [CrossRef]

19. Davis, M.M.; Bjorkman, P.J. T-cell antigen receptor genes and T-cell recognition. Nat. Cell Biol. 1988, 334, 395-402. [CrossRef]

20. Cabaniols, J.P.; Fazilleau, N.; Casrouge, A.; Kourilsky, P.; Kanellopoulos, J.M. Most alpha/beta T cell receptor diversity is due to terminal deoxynucleotidyl transferase. J. Exp. Med. 2001, 194, 1385-1390. [CrossRef]

21. Arstila, T.P.; Casrouge, A.; Baron, V.; Even, J.; Kanellopoulos, J.; Kourilsky, P. A direct estimate of the human alphabeta T cell receptor diversity. Science 1999, 286, 958-961. [CrossRef]

22. Gras, S.; Kjer-Nielsen, L.; Burrows, S.R.; McCluskey, J.; Rossjohn, J. T-cell receptor bias and immunity. Curr. Opin. Immunol. 2008, 20, 119-125. [CrossRef] [PubMed]

23. Valkenburg, S.A.; Josephs, T.M.; Clemens, E.B.; Grant, E.; Nguyen, T.H.O.; Wang, G.C.; Price, D.; Miller, A.; Tong, S.; Thomas, P.G.; et al. Molecular basis for universal HLA-A*0201-restricted CD8+ T-cell immunity against influenza viruses. Proc. Natl. Acad. Sci. USA 2016, 113, 4440-4445. [CrossRef] [PubMed]

24. Venturi, V.; Kedzierska, K.; Price, D.A.; Doherty, P.C.; Douek, D.C.; Turner, S.J.; Davenport, M.P. Sharing of T cell receptors in antigen-specific responses is driven by convergent recombination. Proc. Natl. Acad. Sci. USA 2006, 103, 18691-18696. [CrossRef]

25. Garcia, K.C.; Adams, J.J.; Feng, D.; Ely, L.K. The molecular basis of TCR germline bias for MHC is surprisingly simple. Nat. Immunol. 2009, 10, 143-147. [CrossRef]

26. Lineburg, K.E.; Grant, E.J.; Swaminathan, S.; Chatzileontiadou, D.S.M.; Szeto, C.; Sloane, H.; Panikkar, A.; Raju, J.; Crooks, P.; Rehan, S.; et al. CD8 ${ }^{+} \mathrm{T}$ cells specific for an immunodominant SARS-CoV-2 nucleocapsid epitope cross-react with selective seasonal coronaviruses. Immunity 2021, 54, 1055-1065.e5. [CrossRef]

27. Grant, E.; Josephs, T.M.; Loh, L.; Clemens, E.B.; Sant, S.; Bharadwaj, M.; Chen, W.; Rossjohn, J.; Gras, S.; Kedzierska, K. Broad CD8+ T cell cross-recognition of distinct influenza A strains in humans. Nat. Commun. 2018, 9, 5427. [CrossRef] [PubMed]

28. Kedzierska, K.; Turner, S.J.; Doherty, P.C. Conserved T cell receptor usage in primary and recall responses to an immunodominant influenza virus nucleoprotein epitope. Proc. Natl. Acad. Sci. USA 2004, 101, 4942-4947. [CrossRef] [PubMed]

29. Thompson, J.D.; Higgins, D.G.; Gibson, T.J. CLUSTAL W: Improving the sensitivity of progressive multiple sequence alignment through sequence weighting, position-specific gap penalties and weight matrix choice. Nucleic Acids Res. 1994, 22, 4673-4680. [CrossRef]

30. Szeto, C.; Chatzileontiadou, D.S.M.; Nguyen, A.T.; Sloane, H.; Lobos, C.A.; Jayasinghe, D.; Halim, H.; Smith, C.; RiboldiTunnicliffe, A.; Grant, E.J.; et al. The presentation of SARS-CoV-2 peptides by the common HLA-A*02:01 molecule. iScience 2021, 24, 102096. [CrossRef]

31. Chatzileontiadou, D.S.M.; Szeto, C.; Jayasinghe, D.; Gras, S. Protein purification and crystallization of HLA-A*02:01 in complex with SARS-CoV-2 peptides. STAR Protoc. 2021, 2, 100635. [CrossRef] [PubMed]

32. Aragão, D.; Aishima, J.; Cherukuvada, H.; Clarken, R.; Clift, M.; Cowieson, N.P.; Ericsson, D.J.; Gee, C.L.; Macedo, S.; Mudie, N.; et al. MX2: A high-flux undulator microfocus beamline serving both the chemical and macromolecular crystallography communities at the Australian Synchrotron. J. Synchrotron Radiat. 2018, 25, 885-891. [CrossRef]

33. Kabsch, W. Xds. Acta Crystallogr. D Biol. Crystallogr. 2010, 66, 125-132. [CrossRef]

34. McCoy, A.J.; Grosse-Kunstleve, R.W.; Adams, P.D.; Winn, M.D.; Storoni, L.C.; Read, R.J. Phaser crystallographic software. J. Appl. Crystallogr. 2007, 40, 658-674. [CrossRef] 
35. Winn, M.D.; Ballard, C.C.; Cowtan, K.D.; Dodson, E.J.; Emsley, P.; Evans, P.R.; Keegan, R.M.; Krissinel, E.B.; Leslie, A.G.; McCoy, A.; et al. Overview of the CCP4 suite and current developments. Acta Crystallogr. D Biol. Crystallogr. 2011, 67 Pt 4, $235-242$. [CrossRef] [PubMed]

36. Gras, S.; Saulquin, X.; Reiser, J.-B.; Debeaupuis, E.; Echasserieau, K.; Kissenpfennig, A.; Legoux, F.; Chouquet, A.; Le Gorrec, M.; Machillot, P.; et al. Structural Bases for the Affinity-Driven Selection of a Public TCR against a Dominant Human Cytomegalovirus Epitope. J. Immunol. 2009, 183, 430-437. [CrossRef]

37. Emsley, P.; Lohkamp, B.; Scott, W.; Cowtan, K.D. Features and development of Coot. Acta Crystallogr. Sect. D Biol. Crystallogr. 2010, 66, 486-501. [CrossRef]

38. Bricogne, G.; Blanc, E.; Brandl, M.; Flensburg, C.; Keller, P.; Paciorek, W.; Roversi, P.; Sharff, A.; Smart, O.S.; Vonrhein C.W.T.O.; et al. Buster Version 2.10; Global Phasing Ltd.: Cambridge, UK, 2011.

39. Day, E.B.; Guillonneau, C.; Gras, S.; La Gruta, N.; Vignali, D.A.A.; Doherty, P.C.; Purcell, A.; Rossjohn, J.; Turner, S.J. Structural basis for enabling T-cell receptor diversity within biased virus-specific CD8+ T-cell responses. Proc. Natl. Acad. Sci. USA 2011, 108, 9536-9541. [CrossRef] [PubMed]

40. Cole, D.; Yuan, F.; Rizkallah, P.J.; Miles, J.; Gostick, E.; Price, D.; Gao, G.F.; Jakobsen, B.K.; Sewell, A.K. Germ Line-governed Recognition of a Cancer Epitope by an Immunodominant Human T-cell Receptor. J. Biol. Chem. 2009, 284, 27281-27289. [CrossRef]

41. Cole, D.; Fuller, A.; Dolton, G.; Zervoudi, E.; Legut, M.; Miles, K.; Blanchfield, L.; Madura, F.; Holland, C.J.; Bulek, A.M.; et al. Dual Molecular Mechanisms Govern Escape at Immunodominant HLA A2-Restricted HIV Epitope. Front. Immunol. 2017, 8, 1503. [CrossRef]

42. Riley, T.P.; Hellman, L.; Gee, M.H.; Mendoza, J.L.; Alonso, J.A.; Foley, K.C.; Nishimura, M.I.; Kooi, C.W.V.; Garcia, K.C.; Baker, B.M. T cell receptor cross-reactivity expanded by dramatic peptide-MHC adaptability. Nat. Chem. Biol. 2018, 14, 934-942. [CrossRef] [PubMed]

43. Coles, C.H.; Mulvaney, R.M.; Malla, S.; Walker, A.; Smith, K.J.; Lloyd, A.; Lowe, K.L.; McCully, M.L.; Hague, R.M.; Aleksic, M.; et al. TCRs with Distinct Specificity Profiles Use Different Binding Modes to Engage an Identical Peptide-HLA Complex. J. Immunol. 2020, 204, 1943-1953. [CrossRef] [PubMed]

44. Sahin, U.; Muik, A.; Vogler, I.; Derhovanessian, E.; Kranz, L.M.; Vormehr, M.; Quandt, J.; Bidmon, N.; Ulges, A.; Baum, A.; et al. BNT162b2 vaccine induces neutralizing antibodies and poly-specific T cells in humans. Nat. Cell Biol. 2021, 595, 572-577. [CrossRef] 